\title{
The Myths of Restoration Ecology
}

\author{
$\underline{\text { Robert H. Hilderbrand }}^{1}, \underline{\text { Adam C. Watts }}^{2}$, and $\underline{\text { April M. Randle }}^{3}$
}

Key Words: carbon copy; command and control; cookbook; ecological restoration; fast forward; field of dreams; myths; resilience; restoration ecology; Sisyphus complex

\section{INTRODUCTION}

Humanity's ever-increasing ability to effect environmental change on a number of spatial and temporal scales requires tough decisions about how we view, value, and manage ecosystems. For example, advances in agriculture that support vastly more people per unit area than hunting and gathering are clearly a positive outcome for society. However, many beneficial land-use practices, including agriculture, may ultimately degrade ecosystems. To function as a society, some amount of ecosystem alteration must occur to support the human population, but we are ultimately dependent on ecosystem services. Our actions both intentionally and unwittingly alter the goods and services of many ecosystems on which we rely, and by entering into this relationship of altering ecosystems, we incur responsibility to our neighbors and to future generations. However, the difficult decisions have largely been avoided by the expectations and confidence in conservation and, in particular, ecological restoration.

Given the widespread alteration of natural systems, it is clear that conservation measures alone will not suffice to protect ecosystem functions, services, and habitat for a large number of species in the future. Conservation has traditionally been a rearguard measure to prevent further degradation rather than a means for increasing resources or natural capital. As such, simple maintenance as opposed to enhancement of ecosystems may often leave ecosystems and species vulnerable. Despite conservation policies such as roadless areas and the "No Net Loss" concept for U.S. wetlands, losses continue to exceed gains (Dahl and Allord 1996), and gains are often not functionally equivalent to losses (Zedler 2000a, National Research Council 2001). Increasing human population growth and resource consumption continue to place additional stresses on systems and demands more capacity and services, rather than simple maintenance of current services. Thus, we must either alter consumption or rely on our ability to create, restore, and enhance ecosystems and their services.

Despite our dependence on healthy ecosystems, society has made the decision to continue life as usual until a loss of valued goods and services is realized; then, society will expect and rely on science to clean up the mess and make it look natural. Many government policies concerning development and extractive resource use already assume the ability to mitigate ecosystem damage through the restoration of degraded land or creation of new habitats. However, many restorations are not successful either in structure (Lockwood and Pimm 1999) or function (Kentula 1996, Zedler and Callaway 1999) when compared with reference ecosystems. Such results underscore the need to evaluate our underlying beliefs and expectations in restoration.

The incredible complexity of nature forces us to simplify the systems we study in order to develop theory and generalities by reducing them to understandable subsets. Although we cannot function without theory and conceptual models, their creation often ignores the variability that is so important to accurately describe, predict, and recreate current and future system attributes. In essence, restoration ecology strives to (re-)create complex systems from simplified guiding principles 
or myths. Failure to recognize the limitations and tacit assumptions can lead to failures because of the over-application of over-simplified concepts to complex systems (Holling 1995, Holling and Meffe 1996). We believe the same is true in ecological restoration.

We believe that many unsatisfactory restorations result from a failure to recognize and address uncertainty, and from a focus on inappropriate time scales. Ecological restoration is trying to do in a matter of years what takes decades or centuries under natural conditions. Expecting complete restoration on human time scales is unreasonable, even where full recovery may eventually occur. Nonetheless, many of our underlying beliefs tacitly assume that systems will return to a "natural" state in fairly short order if they are just nudged in the right direction through adjustments to physical attributes or by regulating species composition. Additional problems arise in defining what is "natural" and in our inability to accept that systems are dynamic and may have multiple trajectories leading to numerous possible outcomes. Finally, because we are extrapolating from oversimplified concepts, ignoring uncertainty may result in surprise and failure because we have not created a system capable of adapting or responding to future drivers or events. Therefore, restorations should not be one-time events, but are likely to require periodic attention and adaptive management to increase the chances of responsive, adaptive, and successful projects.

Based on our experiences as researchers and practitioners in conservation and restoration ecology, we propose five central myths (Table 1) under which many ecological restoration and management projects seem to be conceived and implemented. Myths have value because they help us to organize and understand complex systems and phenomena. Identifying myths can help make the tacit explicit by revealing assumptions that are otherwise hidden (Holling 1982). However, they remain simplified and potentially misguided models for understanding and application (Holling 1982, Timmerman 1986). The first Myth, the Carbon Copy, addresses the goal-setting process, and as such, it forms the basis of how restorations are evaluated. The Carbon Copy is closely tied to the remaining four myths, which involve the process of restoration and management: the Field of Dreams; Fast Forwarding; the Cookbook; and Command and Control: the Sisyphus Complex. We believe that describing these myths will be useful in understanding how some management or restoration strategies are conceived, designed, and implemented. For example, adherence to different myths may direct actions in divergent directions, as could be the case when choosing between a focus on ecosystem structure (Carbon Copy) or on key processes (Field of Dreams). Examining these myths may also help us better understand why some restoration projects do not meet our expectations. In the pages below, we briefly describe each myth and its assumptions, and give examples where the myth exists.

Our objective is not to abandon what we propose to be prevalent myths in ecological restoration-there are elements of truth in each-but to recognize that there are tacit assumptions associated with each myth. Failure to recognize these assumptions can lead to conflict and disappointing results despite large expenditures of time and effort. Our challenge is to recognize the limitations and not accept sometimes dogmatic beliefs without critical examination. We do not claim that every project is rooted in myth, but suggest that many perceived failures may be traced to over-reliance on one or more of the myths. We do not condemn restoration ecology, but rather provide a means of selfexamination so readers can identify from their own experiences what worked and possible reasons for perceived failures.

\section{THE MYTH OF THE CARBON COPY}

The myth of the Carbon Copy relates to the selection of restoration goals and end points, and maintains that we can restore or create an ecosystem that is a copy of a previous or ideal state. The myth is rooted in the Clementsian (1936) idea that ecosystems develop in a predictable fashion toward a specified, static, end point or climax. Accordingly, any disturbance or degrading activity will reset the system, resulting in a phase of rebuilding and a return to the previous trajectory of ecosystem development. However, restoration sites are different from those where secondary succession occurs after disturbance (Zedler 2000b), and restoring or creating an ecosystem of specific composition becomes quite difficult. Most successes appear to be only transitory (Lockwood and Pimm 1999). Despite the shortcomings, the myth of a carbon copy persists in ecological 
Table 1. The myths of restoration and their core issues

\begin{tabular}{ll}
\hline \hline Restoration Myth & Core Issues \\
\hline Carbon Copy & Community assembly predictable; a single endpoint exists \\
Field of Dreams & $\begin{array}{l}\text { Sole focus on physico-chemical conditions; } \\
\text { systems self-organize }\end{array}$ \\
Fast Forward & $\begin{array}{l}\text { Succession and ecosystem development can be accelerated } \\
\text { Cookbook }\end{array}$ \\
$\begin{array}{l}\text { Command and Control: } \\
\text { Sisyphus Complex }\end{array}$ & $\begin{array}{l}\text { Methodology overused and not sufficiently validated } \\
\text { problem }\end{array}$
\end{tabular}

restoration. The main reason is that the underpinnings of restoration ecology involve ecological succession and assembly rules (Young 2000), which tend to reinforce subconsciously the concept of a static, climax end point. Indeed, van der Valk (1998) described restoration as accelerated succession. Ecology is rich with examples of succession (Glenn-Lewin et al. 1992), and there is little doubt of its importance in community and ecosystem development (Odum 1969), or potential in restoration (e.g., van der Valk 1998). The main issue is the extent to which succession is equilibrial and can be predicted or controlled to arrive at a predefined state under human time scales. Most landscapes are a mosaic of different vegetation types that shift through both space and time (Bormann and Likens 1979, Pickett and White 1985), and identifying a single state as the only end point is not realistic for most systems.

The myth of the Carbon Copy has influenced resource agencies, such as the U.S. National Park Service, that have mandates to restore and manage some systems to pre-settlement conditions. At its extreme, the Carbon Copy emphasizes a natural or primeval state that existed before European settlement, and becomes the restoration or management objective. As the natural state existed before corruption by modern influences or before a need for restoration, its return is the objective. Although the purpose of restoration and management outside of legislative mandates should guide the goals and end points, a de facto end point is all too often what the system was like in an undisturbed state.
Restoration to a pre-disturbance state may be desirable when concerns are for the "naturalness" of the system, but many difficulties exist during implementation. Few would debate that a predisturbance state is, in most cases, preferable to a degraded one, but the ability to (re-)create a system resembling pre-disturbance may be difficult, if not impossible. Given the sheer number of non-native species that have invaded and been integrated into virtually every ecosystem, it is arguably impossible to achieve a pre-settlement target condition. Even if such a goal could be achieved, selection of the appropriate target remains in question-do we restore for the ecosystem of $1500 \mathrm{AD}, 500 \mathrm{AD}$, or 1000 BC? Another difficulty arises when the underlying parameters and drivers have changed (e. g., Ehrenfeld 2000) or the system is too degraded to achieve pre-disturbance conditions (Hobbs and Norton 1996). Changes such as a rise in sea level, atmospheric acid deposition, and altered hydrology because of urbanization, dams, and water withdrawals may all substantially alter both structure and function as a result of changes in salinity, soil and water chemistry, and hydrography and geomorphology, respectively. Thus, we may aim at a target that is not only moving, but also at a target that is no longer attainable at a specific locale.

Tension and conflict arise when the Carbon Copy is an unrealistic or inappropriate goal. Predisturbance or "pristine" conditions are often in conflict with stakeholder wishes, particularly in more urbanized situations (Shore 1997). Even setting goals that recognize multiple end points can be politically and socially problematic when various stakeholders each desire a different and conflicting 
result. In these cases, a pre-disturbance condition may not represent the best solution, when the objective is to maximize an ecosystem service, function, or aesthetic. Rather than focus on restoring to some primeval state, a more profitable approach would be to accept that ecosystems are dynamic and focus on repairing damaged systems to the extent possible (Hobbs and Harris 2001).

The Carbon Copy myth prevails in extractive resource industries, such as forestry and mining, and its foundations are used as arguments to justify access to resources in undisturbed environmentsthe belief being that these systems will return to their previous state after disturbance. Although few ecologists pretend that the more destructive forms of mining can be fully restored, the belief in this ability is promoted by those backing the extraction industries. Despite limited success, the Carbon Copy myth has resurged in the USA in the form of the "No Net Loss" paradigm of wetland protection policy and mitigation (Zedler 1996), which assumes that created or restored wetlands provide equivalent ecological services, function, and value as those destroyed. Although success stories exist, many now consider the assumptions invalid because few created or restored wetlands have achieved structure or function equivalent to existing wetlands (Zedler and Callaway 1999, National Research Council 2001, Seabloom and van der Valk 2003), and natural wetlands continue to disappear without equivalent replacement (Whigham 1999).

An alternative to creating a carbon copy of species complement is to create a system equivalent in function to the pre-disturbance state. Restored systems can be functionally superior to predisturbance systems, as in the case of wetlands engineered for nutrient removal (e.g., Peterson 1998). The growing field of ecological engineering is rich with examples of such enhanced systems (Ansola et al. 1995, Kadlec and Knight 1996, Knowlton et al. 2002, Kangas 2003), and will become ever more important to society as we continue to degrade natural systems. Functional replacement could be more easily accomplished than replacement of taxonomic composition because of the shared ecological function of many species (Stanturf et al. 2001). The danger in this approach is that some functions may be enhanced yet more subtle functions (e.g., species' habitats) or indirect interactions (e.g., heightened predation due to habitat differences) may suffer. Questions that remain include the resilience of functional replacements to disturbances and their acceptability to society. The heightened public awareness of invasive species modifying ecosystems and the potentially foreign look of a functional replacement may be socially unpalatable.

\section{THE MYTH OF THE FIELD OF DREAMS}

The Field of Dreams stems from the notion that all one needs is the physical structure for a particular ecosystem, and biotic composition and function will self-assemble-if you build it, they will come. Similarly, restoration of a process, such as fire or hydrologic regime, is expected to re-create predisturbance structure. Although re-creating the physical template and drivers are a necessary first step, it is rarely a final step and sometimes a misstep (e.g., Smith 1997). A fundamental assumption of this myth is that the community and ecosystem assembly process follow a repeatable trajectory, and uncertainty is implicitly ignored. Although there are some encouraging generalizations emerging about community assembly (Christensen and Peet 1984, Drake 1990, Keddy 1999), community assembly is in many ways reminiscent of Rudyard Kipling's (1902) Just So Stories: communities are historically contingent products (Parker 1997), and much uncertainty still exists given the influences of initial conditions (Grace 1987) and stochastic or neutral assembly (Hubbell 2001). Failure to accept uncertainty and the dynamic nature of community assembly can lead to the traps of the Carbon Copy myth.

The Field of Dreams approach is common in both wetland and stream restoration, where emphasis is often on re-creating physical attributes with little attention paid to biotic responses. For example, the Rosgen approach (Rosgen 1994, 1998) is probably the most widely used stream restoration method in North America, but it deals almost exclusively with geomorphic attributes of stream channels. Restoration goals in systems such as urban watersheds often involve preventing streambed erosion and destruction of buried utilities, such as sewer and water lines. Although stabilization of the stream channel is quite important, stopping at a geomorphic end point is similar to ensuring that mining excavations in terrestrial landscapes are filled after a job is completed, and then not proceeding with revegetation. Similar examples exist for wetland restorations (van der Valk 1998), where the concept of self-design (Mitsch and 
Wilson 1996, Mitsch et al. 1998) is embraced after the hydrologic conditions are restored. Restoration sites do become revegetated, but may be of different species composition and degree of cover (Seabloom and van der Valk 2003), owing to dispersal limitations of many wetland species (Galatowitsch and van der Valk 1996). Thus, the effectiveness of self-design depends on the restoration goals, but adopting a concept of self-design does implicitly recognize and embrace the existence of multiple end points.

An effective restoration of the physical variables will create the template for biotic recovery, but physical structure does not always beget biotic structure, and biotic structure does not necessarily result in similar ecosystem functions across sites. The concept of self-organization, or self-design, is an intuitively appealing approach and is very attractive to resource managers who have limited time and budgets. A self-assembling ecosystem would substantially cut down on the amount of effort required to restore ecosystems, and we feel this is why the Field of Dreams is commonly employed. However, its effectiveness in restoring structure and function is still debatable (Simenstad and Thom 1996, Zedler and Callaway 1999, National Research Council 2001), and restored areas may be quite different from undisturbed sites (Seabloom and van der Valk 2003). In defense of self-assembly, composition of restored sites is expected to approach reference sites given sufficient time (Mitsch 1997). Effective restoration using this approach must overcome issues of recolonization and dispersal, stochasticity in community assembly, and assembly of energy transfer pathways. One commonly used strategy to circumvent these limitations is to jumpstart the process by adding organisms, but our understanding of accelerating ecosystem development is incomplete and may lead to the myth of Fast-Forwarding.

\section{THE MYTH OF FAST-FORWARDING}

The myth of Fast-Forwarding is based on the idea that one can accelerate ecosystem development by controlling pathways, such as dispersal, colonization, and community assembly, to reduce the time required to create a functional or desired ecosystem. This idea stems from the initial floristics model of succession (Egler 1954) in which the process of ecosystem development is accelerated by controlling initial species composition and succession to achieve the desired end point (van der Valk 1998). The major assumption is that we can reliably recreate key processes and links between the biota and physical environment. A driving force behind this approach is the need to demonstrate rapid recovery of disturbed lands in order, for example, to have insurance or mitigation performance bonds returned quickly.

Many types of restoration projects justifiably use a fast-forwarding approach to jumpstart the recovery process by using species desired in the ecosystem. As most restorations include plantings to get the ball rolling and stabilize the terrain, it is logical to try to advance the successional process, and this is why the practice is so common. However, relying on the premise that fast-forwarding will produce the desired ecosystem trajectory and speed the recovery process may result in disappointment. Little evidence exists for achieving desired trajectories or functions within the shortened time spans promised by fast-forwarding (Simenstad and Thom 1996, Zedler and Callaway 1999, Campbell et al. 2002, Wilkins et al. 2003). As with other myths, there is some element of truth, and successes using fastforwarding have occurred (e.g., Clewell 1999). Successful projects typically require multiple plantings and a considerable amount of attention to ensure survival of plantings in systems that may be "premature" for the species' arrival. Even when successful, certain ecological processes, such as the development of tree hollows for cavity-nesting animals, soil development, mycorrhyzal associations, and hydrologic regimes, present more difficult challenges and may take years or decades. Mitsch and Wilson (1996), for example, point out that the 5-year span in which "quick-fix' wetlands" are expected to become sufficient replacements for lost or damaged areas is improbably short, and that 1520 years is a much more realistic expectation. Longterm monitoring (5-15 years) of restoration projects is indicating that a more likely time horizon is several decades for a restoration to resemble a predisturbance target (Zedler and Callaway 1999, Wilkins et al. 2003). Many ecological restoration projects-even ecological restoration itself-aim for rapid progress from a damaged state toward some more-or-less specific target. There is nothing inherently wrong with such a goal, however, we should not be so intent on attaining a specific point that the system's potential future state (i.e., after restoration efforts cease and natural processes take over) is ignored. 


\section{THE MYTH OF THE COOKBOOK}

When a particular restoration experience is successful in one area or ecosystem, we naturally want to apply the same techniques in other restoration efforts; after all, science has little relevance if the results are not repeatable. We refer to the over-use or continued use of a locally unsuccessful restoration prescription because it worked somewhere else, or is in the published literature, as the myth of the Cookbook. Perpetrators of this myth assume that similar physical and ecological systems respond identically and predictably to restoration techniques. Although a reasonable starting point, systems that appear very similar may exhibit considerable differences in variables that regulate slow processes (e.g., carbon storage), and the same management prescription applied to two such systems may have vastly different results. The difficulty arises when approaches are adopted that ignore uncertainty. A non-adaptive technique forces us down a path with few alternatives to a changing world.

The myth of the cookbook arises often in stream restoration, and possibly wetland restoration and creation, where recipes for restoration exist (Rosgen 1998). Cookbook approaches seem to be most often present in engineering approaches to restorations. We are not denouncing the goal of standard methods, but we believe that there is still too much uncertainty to commit totally to one technique in a given situation. Even in chemistry, where well developed standard methods exist, a good yield from a single reaction may be $90 \%$ and a complex set of reactions may yield less than $50 \%$, meaning that half the reactions did not go as they should. Given the complexity of many restorations, the practice is fairly successful relative to the chemistry analogy. However, incomplete chemical reactions can be precipitated, discarded, or otherwise dealt with quickly and inexpensively, but we do not have the luxury to treat degraded systems similarly, nor can we accept such a failure rate given the high financial cost. The positive side is that systems are rarely in worse condition after a restoration even if the project did not meet the stated goals.

To resource professionals plagued by a lack of information, time, and budget, cookbook approaches may be the only realistic approach. The opportunity to use a successful restoration effort as a template for a similar system is a start, and may be preferable to inaction. It may also be advisable to replicate certain elements of proven restoration techniques, because some valid generalities may be made concerning the responses of a wide range of ecosystems to the same actions (Zedler 2000a). However, idiosyncrasies of each system (unique ecological histories, differing assembly rules, or even differing functional roles of components of two similar ecosystems) may result in elements of surprise and crisis when a uniform, cookbook approach is used without detailed knowledge of the ecological characteristics of the ecosystem to be restored. As the community or ecosystem to be restored becomes less and less similar to the system in which a given restoration approach was successful, the potential for unforeseen responses and failure increases dramatically.

By defining the myth of the Cookbook, we do not advocate reinventing the wheel with every new project. One of the major goals of restoration ecology is to develop a suite of methods that can be used in a given situation to best effect. We believe this desire or belief in repeatable methods is why the cookbook remains. Problems arise when a method is over used or used in the wrong situation just because the method exists and is understood. A number of approaches (e.g., Kershner 1997, Clewell et al. 2000, Richter et al. 2003) provide general guidance, but allow for site-specific adjustments to deal with uncertainty. A more cautious approach, acknowledging our inability to predict the exact response of an ecosystem to manipulation, would be the application of a varied management or restoration regime across a landscape. Techniques aimed at discovering and mimicking the character of natural systems would be more likely to find successful solutions (Mitsch and Wilson 1996), while likely contributing to the resilience of the system (Holling et al. 2002).

\section{THE MYTH OF COMMAND AND CONTROL AND THE SISYPHUS COMPLEX}

The myth of Command and Control (Holling and Meffe 1996) describes the "pathology of natural resources management" where goals are achieved by active intervention and unending control, or manipulation of physical and biological components of the ecosystem. This myth, articulated by Holling and Meffe (1996), assumes we have the knowledge, abilities, and foresight to actively control ecosystem structure and function to manage for a particular ecosystem state indefinitely into the future. Exerting 
command and control invariably decreases system resilience by reducing the range of natural variation and adaptive capacity for the system to respond to disturbances (Gunderson 2000). As resilience decreases, the likelihood of a disturbance shifting the system into an undesired or degraded state increases, and control is wrested from the manager.

Practice of Command and Control recalls the story of Sisyphus, one of the most unenviable characters in Greek mythology because he is compelled by the Gods to forever push a heavy boulder uphill. Just as he nears the top, Sisyphus becomes exhausted, and the boulder rolls back down to the plain below, where Sisyphus must begin again. Like Sisyphus, we can become trapped in an endless cycle of effort to compel ecosystems to remain in single, transient, or unstable states, resulting in repeated episodes of surprise and crisis that can mimic the ball-in-cup analogy of system dynamics (Lewontin 1969, Holling 1973, Beisner et al. 2003), with the ball rolling around the cup and away from the manager's desired state. The Sisyphus Complex emerges when we act through Command and Control to hold a dynamic system static or force a system to exist in a transient state. In any restoration, some amount of Command and Control is required to perform the restoration. Additional nudges to physical or biological components will likely occur in the years after the restoration as well. There is nothing wrong with some tinkering-we cannot exist without having some effect on our surroundings. Actions to be avoided are those that are long term in nature or will decrease the natural range of variability in key processes, such as fire regime or hydrology.

The Sisyphus Complex often occurs when the dominant, large-scale drivers of the system have changed and are either not noticed or conveniently ignored. When we fall into the Sisyphus Complex, we become fixated on treating symptoms rather than the root of the problem and so become susceptible to failure. Urban stream restorations often occur in response to severely eroded stream channels, and a more flashy hydrograph that results from increases in impervious surface area higher in the watershed. Many such restorations fail (sometimes multiple times) despite tremendous expense and effort, because the altered driver (the hydrograph) and the root cause (impervious surfaces) were not addressed. Other general examples include coastal beach restoration in the face of ongoing, natural erosion; rare species stocking/reintroduction programs that ignore the root causes of rarity; and attempting to direct succession to end points incompatible with environmental conditions. Sometimes the Sisyphus Complex results from social or political mandates to do something despite credible science to the contrary. In these situations, we must make every effort for science to influence decision making so that the inevitable repeated failures are not perceived as employment justification or incompetence on the part of science.

\section{MOVING BEYOND THE MYTHS}

Myths have value because they help us to organize and understand complex systems and phenomena, and provide a starting point toward the restoration and management of degraded ecosystems. We feel this is why the myths of restoration exist and persist. We hope that proposing these myths (whether the reader agrees with them or not) will begin a dialog leading to a deeper thinking about and greater understanding of natural systems and advancing the science of restoration ecology and management.

Identifying myths has several implications for restoration design. A common theme in the myths is a failure to recognize and address uncertainty. Ignoring uncertainty often results in surprise and failure, because we have not created a system capable of adapting or responding to future drivers or chance events, and we are unable to exert ultimate control over the system. An alternative approach would be designing for resilience by planning for surprise. Although we cannot anticipate all future events, we can manage and restore in ways that allow for uncertainty. Planning for resilience should allow systems a greater ability to deal with and recover from surprise and future change by focusing on a diversity of approaches, functions, and taxa.

When viewed in the context of designing for resilience, restorations become experiments in adaptive management or adaptive restoration (Zedler 2000b). Restoration projects with decision points along the way allow for critical assessment and possible intervention with contingency plans if things are not proceeding appropriately. Rapid learning can also be achieved by using a diversity of restoration techniques and approaches likely to be successful within the larger restoration. Assessing the performance of multiple approaches may increase cost, but it allows for testing multiple hypotheses and adaptive learning, and may cost less in the long run. If more than one approach is 
successful, the restoration toolbox quickly expands, and much about the system is learned. If, however, no approach works, we will have quickly learned the inability of several techniques compared with the time it would take to gain the same results one restoration at a time. The challenge is to implement and design multiple approaches so that each can be assessed independently of others, as well as independently of adaptive responses that may occur along decision points after periodic evaluations. Multiple approaches within a larger restoration will also likely increase system resilience because the system created by each approach may have differential response to and recovery from disturbances. Maximizing species diversity in restorations is likely to increase response diversity (Elmqvist et al. 2003) and may increase the likelihood of a restoration containing species resistant or resilient to future conditions and disturbances. Although the concept that diversity begets ecosystem stability may itself be an emerging myth, it seems worth pursuing for other reasons as well.

Recognizing mythologies may also aid the goalsetting process. The forest primeval no longer exists and may not be attainable-exotic species, historic disturbance regimes, and changes in climatic and landscape drivers all serve to ensure that there never was, and probably never will be a single, repeatable end point. More realistically, goals should include multiple scientifically defensible end points of functional or structural equivalence. Although maintaining biotic or ecological integrity is a noble goal, invasive species are too entrenched in many systems to consider their presence a restoration failure, particularly when some may have similar roles as native species. Providing for alternative solutions to future conditions by setting multiple end points implicitly increases resilience by increasing the adaptive capacity and response diversity of the system. In addition to being more realistic and attainable, having several possible end points may also reduce tension within and among practitioners and stakeholders.

Restoration projects should expand goals and expectations beyond quantitative targets or ranges for ecological attributes, such as vegetation density, biogeochemical processes, and hydroperiods. Approaches that consider ecological capital, connectivity, and variability are likely to improve the ecological resilience of restored systems, and therefore, their ability to absorb disturbances or insults without resulting in a permanent change in fundamental system attributes. One size does not fit all, even when situations may appear very similar. Any ecological restoration or management effort involves both explicit and implicit attempts to prescribe and predict the ecological future of a site. These efforts require extrapolating far beyond our predictive abilities, and we must be aware of our limitations as scientists, as well as our tendency as humans to rely on partial truths and assumptions when implementing ecological restoration and management projects.

We conclude by suggesting a final myth of restoration ecology, but one held by society-the Bionic World. The myth of the Bionic World is a belief that science and technology will solve the pressing issues of human population growth, finite resources, and altered ecosystems. In the Bionic World, degraded landscapes will be fixed or reconstructed with the precision and surety of the "Bionic Woman" and the "Six Million Dollar Man" in the U.S. television shows of the 1970s. If we follow this logic, we have no tough choices to make about how we view and treat our surroundings, and decisions can be put off until the economic markets demand or justify a solution. Let's hope they're right, but until supporting evidence emerges, we must maintain what we have.

Responses to this article can be read online at: http://www.ecologyandsociety.org/vollo/iss 1/art19/responses/

\section{Acknowledgments:}

This work was conducted as part of the Theories for Sustainable Futures Working Group supported by the National Center for Ecological Analysis and Synthesis, a Center funded by the National Science Foundation (Grant \#DEB-94-21535), the University of California at Santa Barbara, and the State of California. The authors thank Guy Barnett, Katia Engelhardt, Lance Gunderson, Buzz. Holling, and two anonymous referees for helpful comments throughout manuscript preparation. R. H. was partially supported by a D. H. Smith Conservation Research Fellowship from The Nature Conservancy. This is publication DHS 2004-07 of the David H. Smith Research Fellowship Program, University of Maryland Center for Environmental Science Appalachian Laboratory scientific contribution 
number 3813.

\section{LITERATURE CITED}

Ansola, G., C. Fernandez, and E. de Luis. 1995. Removal of organic matter and nutrients from urban wastewater by using an experimental emergent aquatic macrophyte system. Ecological Engineering 5:13-19.

Beisner, B. E., D. T. Haydon, and K. Cuddington. 2003. Alternative stable states in ecology. Frontiers in Ecology and the Environment 1:376-382.

Bormann, F. H., and G. E. Likens. 1979. Pattern and process in a forested ecosystem. SpringerVerlag, New York, New York, USA.

Campbell, D. A., C. A. Cole, and R. P. Brooks. 2002. A comparison of created and natural wetlands in Pennsylvania, USA. Wetlands Ecology and Management 10:41-49.

Christensen, N. L., and R. K. Peet. 1984. Convergence during secondary forest succession. Journal of Ecology 72:25-36.

Clements, F. E. 1936. Nature and structure of the climax. Journal of Ecology 24:252-284.

Clewell, A. F. 1999. Restoration of riverine forest at Hall Branch on phosphate-mined land, Florida. Restoration Ecology 7:1-14.

Clewell, A., J. Rieger, and J. Munro. 2000. Guidelines for developing and managing ecological restoration projects. Society for Ecological Restoration, Tucson, Arizona, USA.

Dahl, T. E., and G. J. Allord. 1996. History of wetlands in the conterminous United States. Pages 19-26 in J. D. Fretwell, J. S. Williams, and P. J. Redman, editors. National water summary on wetland resources. United States Geological Survey. Water Supply Paper 2425. Reston, Virginia, USA.

Drake, J. A. 1990. Communities as assembled structures: do rules govern pattern? Trends in Ecology and Evolution 5:159-164.
Egler, F. E. 1954. Vegetation science concepts. I. initial floristic composition-a factor in old-field vegetation development. Vegetatio 4:412-417.

Ehrenfeld, J. G. 2000. Evaluating wetlands within an urban context. Ecological Engineering 15:253265.

Elmqvist, T., C. Folke, M. Nystrom, G. Peterson, J. Bengtsson, B. Walker, and J. Norberg. 2003. Response diversity, ecosystem change, and resilience. Frontiers in Ecology and the Environment 1:488-494.

Galatowitsch, S., and A. van der Valk. 1996. The vegetation of restored and natural prairie wetlands. Ecological Applications 6:102-112.

Glenn-Lewin, D. C., R. K. Peet, and T. T. Veblen. 1992. Plant succession: theory and prediction. Chapman and Hall, London, UK.

Grace, J. B. 1987. The impact of preemption on the zonation of two Typha species along lakeshores. Ecological Monographs 57:283-303.

Gunderson, L. H. 2000. Resilience in theory and practice. Annual Review of Ecology and Systematics 31:425-439.

Hobbs, R. J., and J. A. Harris. 2001. Restoration ecology: repairing the Earth's ecosystems in the new millennium. Restoration Ecology 9:239-246.

Hobbs, R. J., and D. A. Norton. 1996. Towards a conceptual framework for restoration ecology. Restoration Ecology 4:93-110.

Holling, C. S. 1973. Resilience and stability of ecological systems. Annual Review of Ecology and Systematics 4:1-23.

Holling, C. S. 1982. Myths of ecology and energy. Pages 8-16 in L. C. Ruedisili and M. W. Firebaugh, editors. Perspectives on energy: issues, ideas, and environmental dilemmas. Oxford University Press, New York, New York, USA.

Holling, C. S. 1995. What barriers? What bridges? Pages 3-34 in L. H. Gunderson, C. S. Holling, and S. S. Light, editors. Barriers and bridges to the renewal of ecosystems and institutions. Columbia University Press, New York, New York, USA. 
Holling C. S., S. R. Carpenter, W. A. Brock, and L. H. Gunderson. 2002. Discoveries for sustainable futures. Pages 395-418 in L. H. Gunderson, and C. S. Holling, editors. Panarchy: understanding transformations in human and natural systems. Island Press, Washington, D.C., USA.

Holling, C. S., and G. K. Meffe. 1996. Command and control and the pathology of

natural resource management. Conservation Biology 10:328-337.

Hubbell, S. P. 2001. The unified neutral theory of biodiversity and biogeography. Monographs in Population Biology 32. Princeton University Press. Princeton, New Jersey, USA.

Kadlec, R. H., and R. L. Knight. 1996. Treatment wetlands. Lewis Publishers, Boca Raton, Florida, USA.

Kangas, P. C. 2003. Ecological engineering: principles and practice. Lewis Publishers, Boca Raton, Florida, USA.

Keddy, P. 1999. Wetland restoration: the potential for assembly rules in the service of conservation. Wetlands 19:716-732.

Kentula, M. E. 1996. Wetland restoration and creation. Pages 87-92 in J. D. Fretwell, J. S. Williams, and P. J. Redman, editors. National water summary on wetland resources. United States Geological Survey. Water Supply Paper 2425. Reston, Virginia, USA.

Kershner, J. L. 1997. Setting riparian/aquatic restoration objectives within a watershed context. Restoration Ecology 5:15-24.

Kipling, R. 1902. Just so stories. Airmont Publishing Company, New York, New York, USA.

Knowlton, M. F., C. Cuvellier, and J. R. Jones. 2002. Initial performance of a high capacity surfaceflow treatment wetland. Wetlands 22:522-527.

Lewontin, R. C. 1969. The meaning of stability. Brookhaven Symposium in Biology 22:13-24.

Lockwood, J. L., and S. L. Pimm. 1999. When does restoration succeed? Pages 363-392 in E.
Weiher and P. A. Keddy, editors. Ecological assembly rules: perspectives, advances and retreats.Cambridge University Press, Cambridge, UK.

Mitsch, W. J. 1997. Olentangy River Wetland Research Park at the Ohio State University. Annual Report 1996. School of Natural Resources, Ohio State University, Columbus, Ohio, USA.

Mitsch, W. J., and R. F. Wilson. 1996. Improving the success of wetland creation and restoration with know-how, time, and self-design. Ecological Applications 6:77-83.

Mitsch, W. J., X. Wu, R. W. Nairn, P. E. Weihe, N. Wang, R. Deal, and C. E. Boucher. 1998. Creating and restoring wetlands. BioScience 48:1019-1030.

National Research Council. 2001. Compensating for wetland losses under the Clean Water Act. National Academy Press, Washington, D.C., USA.

Odum, E. P. 1969. The strategy of ecosystem development. Science 164:262-270.

Parker, V.T. 1997. The scale of successional models and restoration objectives. Restoration Ecology 5:301-306.

Peterson, H. G. 1998. Use of constructed wetlands to process agricultural wastewater. Canadian Journal of Plant Science 78:199-210.

Pickett, S. T. A., and P.S. White. 1985. The ecology of natural disturbance and patch dynamics. Academic Press, New York, New York, USA.

Richter, B. D., R. Matthews, D. L. Harrison, and R. Wigington. 2003. Ecologically sustainable water management: managing river flows for ecological integrity. Ecological Applications 13:206224.

Rosgen, D. L. 1994. A classification of natural rivers. Catena 22:169-199.

Rosgen, D. L. 1998. River restoration and natural channel design course handbook. Wildland Hydrology, Pagosa Springs, Colorado, USA.

Seabloom, E. W., and A. G. van der Valk. 2003. Plant diversity, composition, and invasion of 
restored and natural prairie pothole wetlands: implications for restoration. Wetlands 23:1-12.

Shore, D. 1997. The Chicago wilderness and its critics. II. Controversy erupts over restoration in Chicago area. Restoration and Management Notes 15:25-31.

Simenstad, C. A., and R. M. Thom. 1996. Functional equivalency trajectories of the restored Gog-Le-Hi-Te estuarine wetland. Ecological Applications 6:38-56.

Smith, S. 1997. Changes in the hydraulic and morphological characteristics of a relocated stream channel. Thesis, University of Maryland, College Park, Maryland, USA.

Stanturf, J. A., S. H. Schoenholtz, C. J. Schweitzer, and J. P. Shepard. 2001. Achieving restoration success: myths in bottomland hardwood forests. Restoration Ecology 9:189-200.

Timmerman, P. 1986. Mythology and surprise in the sustainable development of the biosphere. Pages 436-454 in W. C. Clark and R. E. Munn, editors. Sustainable development of the biosphere. Cambridge University Press, Cambridge, UK.

van der Valk, A. G. 1998. Succession theory and restoration of wetland vegetation. Pages 657-667 in A. J. McComb and J. A. Davis, editors. Wetlands for the future. Gleneagles Publishing, Adelaide, Australia.

Whigham, D. F. 1999. Ecological consequences of wetland preservation, restoration, creation and assessment. Science of the Total Environment 240:31-40.

Wilkins, S., D. A. Keith, and P. Adam. 2003. Measuring success: evaluating the restoration of a grassy eucalypt woodland on the Cumberland Plain, Sydney, Australia. Restoration Ecology 11:489503.

Young, T. P. 2000. Restoration ecology and conservation biology. Biological Conservation 92:73-83.

Zedler, J. B. 1996. Ecological issues in wetland mitigation: an introduction to the forum. Ecological Applications 6:33-37.
Zedler, J. B. 2000a. Progress in wetland restoration ecology. Trends in Ecology and Evolution 15:402407.

Zedler, J. B. 2000b. Handbook for restoring tidal wetlands. CRC Press, Boca Raton, Florida, USA.

Zedler, J. B., and J. C. Callaway. 1999. Tracking wetland restoration: do mitigation sites follow desired trajectories? Restoration Ecology 7:69-73. 